\title{
Frédéric Musso, Albert Camus ou la fatalité des natures
}

\section{Stefano Genetti}

\section{(2) OpenEdition}

\section{Journals}

\section{Edizione digitale}

URL: http://journals.openedition.org/studifrancesi/9334

DOI: 10.4000/studifrancesi.9334

ISSN: 2427-5856

\section{Editore}

Rosenberg \& Sellier

\section{Edizione cartacea}

Data di pubblicazione: 1 juin 2008

Paginazione: 223

ISSN: 0039-2944

\section{Notizia bibliografica digitale}

Stefano Genetti, «Frédéric Musso, Albert Camus ou la fatalité des natures», Studi Francesi [Online], 154

(LII | I) | 2008, online dal 30 novembre 2015, consultato il 08 janvier 2021. URL: http://

journals.openedition.org/studifrancesi/9334 ; DOI: https://doi.org/ERREUR PDO dans /localdata/ www-bin/Core/Core/Db/Db.class.php L.34 : SQLSTATE[HY000] [2006] MySQL server has gone away

Questo documento è stato generato automaticamente il 8 janvier 2021.

\section{(c) (i) (9)}

Studi Francesi è distribuita con Licenza Creative Commons Attribuzione - Non commerciale - Non opere derivate 4.0 Internazionale. 


\title{
Frédéric Musso, Albert Camus ou la fatalité des natures
}

\author{
Stefano Genetti
}

\section{NOTIZIA}

FRÉDÉRIC MUSSO, Albert Camus ou la fatalité des natures, Paris, Gallimard, 2006 («nrf essais»), pp. 200.

1 In nome della terra che accomuna i due scrittori, il saggio del romanziere F. Musso insiste sulle origini algerine di Camus, sulla matrice mediterranea di un immaginario «enraciné dans l'exil» (p. 15) e abitato da figure mitiche quali Prometeo e Ulisse. In dieci capitoli dall'andamento volutamente rapsodico, l'A. ricostruisce un itinerario che dalla solitudine nell'assurdo conduce Camus alla lotta contro ogni forma di terrore. Nel rileggere, spesso alla luce degli avantesti o dei progetti rimasti incompiuti, varie opere - da Le Mythe de Sisyphe a L'Homme révolté, da L'Étranger a La Peste e dalle novelle di L'Exil et le Royaume, L'Hôte in particolare, a La Chute - egli mobilita fonti eterogenee che vanno da Bachelard a Girard, da Agamben a Calasso; moltiplica i paralleli con, tra gli altri, Paul Valéry e George Orwell; ritorna sul vivace dibattito cui le prese di posizione di Camus hanno dato luogo, nonché sugli influssi di cui il suo pensiero e la sua scrittura risentono, da Eraclito a Nietzsche, da Dostoevskij a Rimbaud, mito a un tempo demistificato e alimentato: «le créateur absurde ne tient pas à son œuvre» (p. 121).

Biografemi e testimonianze, considerazioni sulle fonti o sulla critica e digressioni personali si alternano nel contesto di un'argomentazione per così dire pointilliste, che procede per tocchi giustapposti e dove il quadro d'insieme si ricompone a distanza. Nel rievocare gli incontri - talvolta gli scontri - di Camus con Sartre o Pascal Pia, ma anche con Buzzati, con Char, Ponge, Jean Sénac e nel soffermarsi sulla ricezione, immediata o posteriore, dell'opera presso altri scrittori e pensatori - Breton, Paulhan, Gracq, RobbeGrillet, Bourdieu, ecc. - l'A. ridisegna tutto un paesaggio intellettuale. L'ampio spazio accordato agli scritti intimi o alle dichiarazioni occasionali, ai carnets, alla 
corrispondenza, alle interviste, evidenzia l'intento, in polemica contro certe derive iperinterpretative ("Adieu littérature... ", p. 141), di ancorare alle intenzioni e al vissuto dell'uomo un universo letterario che ruota intorno alle parole, annotate dallo stesso Camus, «le monde, la douleur, la terre, la mère, les hommes, le désert, l'honneur, la misère, l'été, la mer» (p. 133). A queste F. Musso aggiunge: «le désir, la femme, l'exil, l'amitié, le bonheur, les animaux [...], le consentement [...], la liberté, l'aube, le silence... $»$ (p. 134). 